\title{
Urban Depopulation in Romania
}

\section{Iulian Adrian SORCARU ${ }^{\star}$}

\begin{tabular}{l}
\hline \multicolumn{1}{c}{ A R T I C L E I N F O } \\
\hline Article history: \\
Accepted March 2020 \\
Available online May 2020 \\
\hline JEL Classification \\
J11, R23 \\
Keywords: \\
Urban depopulation, Migration, \\
Natural balance, Demographic \\
evolution, Aging
\end{tabular}

\begin{abstract}
A B S T R A C T
Depopulation is a process which affects nowadays, not only the rural areas, but also the urban ones, emphasizing the regional disparities in Romania. The study analyses the dynamics of the urban population and county capital cities in Romania during 1992-2019, but also the evolution of the balance of the changes of domicile and natural balance in the urban regions, processes that influenced directly the urban shrinkage. In the same time, the paper focuses on the dynamics of aging and population average age, considered to be the most important effects of urban depopulation. The graphic and cartographic methods were used to highlight as well as possible the results.
\end{abstract}

(C) 2020 EAI. All rights reserved.

\section{Introduction}

Depopulation is one of the most important demographic challenges facing the Europe continent. Although it has been studied in recent studies, published in the last decade, it is a process that has its origin since the begining of the twentieth century.

At the beginning, the process of depopulation was associated with rural areas. Meanwhile, the demographic process related to this situation -emigration of labour force and the negative natural balance- is extending to small and medium-sized towns that have been decreasing in population size in the last twothree decades.

The process is amplified by globalisation, which tend to concentrate capital and activities of high added value in global cities and their areas of influence, thus marginalising the smaller urban areas (Sassen, 1991; Florida, 2002). As a result, the significance of interurban migratory flows from towns and cities at lower levels of the territorial hierarchy to predominant metropolitan areas has increased (Sánchez-Moral et al., 2018; González-Leonardo and López-Gay, 2019).

A recent study published by EU Science Hub reflected that over 50\% of European cities will record a demographic decline and only a third of them will grow by more than $10 \%$ in the next three decades. The research also mapped patterns according to the evolution of urban population in the EU (file://E:/documente/articole\%202018/2020/the-future-of-cities_online.pdf)

In addition to urban demographic decline, ageing is another process that "accompanies" the emigration of labour force. Low fertility rates in small and medium-sized towns must be also included in the loss of qualified human capital, as a consequence of the demographic behaviour of highly educated people. Unfortunately, the high proportion of university degree holders in these towns, who choose to leave and search for better jobs elsewhere, is not compensated by the educational profile of immigrants coming from other regions. Besides their smaller numbers, the latter are less qualified than those who leave. It should be kept in mind that emigration of human capital is no trivial matter since it has very negative consequences for the outflow areas (Docquier and Rapoport, 2012).

If we search for punctual examples, since the beginning of the century, we notice an increasing longdistance mobility among young and educated people from Spain, mainly from the urban regions with more precarious productive systems to more thriving regions of the country and also abroad. The metropolitan area of Madrid is the main receiver of Spain's migrants, most of them being highly educated young people. In the same time, small and medium-sized towns in the interior and north of Spain face demographic decline and educational decapitalisation. The process of depopulation caused by outflows to these urban areas can be applied to other countries of the EU, together with a concomitant exacerbation of already-existing territorial imbalances between regions, Romania being among them.

The transition from the communist to the capitalist period, achieved in Romania in 1990, generated, after thirty years of transition, both positive changes, necessary for the creation of a new identity of the Romanian society, but also negative ones that put their mark especially on the near future. Among the 
negative ones, not only the demographic decline should be in the attention of the researchers, but also the moral degradation of the individuals, the degradation of the interpersonal relations, the behavior in the daily life, the aggression, the corruption, etc.

Romania is facing, from a demographic and social point of view, with a continuous decline in the last three decades, the solutions for stopping it and recovering towards a new demographic balance, being complex. Thus, although various pronatalist policies were adopted, especially after 2000, they proved to be useless, not being followed by major political and economic changes, which would make local and central public institutions more efficient and have the final effect of reducing the population migration.

The demographic evolution of the resident population in Romania during 1990-2018, influenced by the natural and migratory balance, reflects the following conclusions (Table 1):

- the huge decline of the resident population, reached 3.8 million during 1990-2018 and expected to reach 4 million in 2020;

- the net predominance of the decline caused by the external migration during whole period, through the huge waves of emigrants from the first two subperiods (figure 1);

- reducing the decline caused by external migration after 2010 , the parallel increase of the size of the decline caused by natural decrease and the installation of this component as the main "engine" of the country's depopulation;

- the natural decline of the population has much more complex causal factors and mechanisms than migration, with origins in economic, social, cultural, medical and environmental, factors and mechanisms that model the birth and mortality rates of the population over time and are characterized by action displayed in time and rigidity to changes;

- a natural decrease of the population that exceeded 1 million inhabitants and to which is added after 2015 an annual natural decline of 70 thousand inhabitants is more than worrying for the future of the country's population;

- a reduction of the natural decrease by a potential recovery of the birth rate and a decrease of the mortality of the population is an extremely difficult objective to achieve and involves great financial costs.

In this context, in Romania, depopulation, especially after 2000, is no longer a phenomenon that affects only rural regions, but has gradually increased in the urban ones, both in small and medium-sized cities and in large ones. The young population, but especially the educated adults, who form the urban workforce emigrate, either to the capital or to other metropolitan areas outside the country, this migration being not compensated numerically and in terms of the level of education.

Table 1. Dynamics of the Resident Population in Romania during 1990-2018 and its Components

\begin{tabular}{|c|c|c|c|}
\hline \multirow[t]{2}{*}{ Period } & \multirow[t]{2}{*}{ Population decline } & \multicolumn{2}{|c|}{$\begin{array}{c}\text { The contribution of natural decline and } \\
\text { external migration }\end{array}$} \\
\hline & & Natural decline & Net migration \\
\hline \multirow{4}{*}{$\begin{array}{l}1990-2002 \\
\text { (13 years) }\end{array}$} & \multicolumn{3}{|l|}{ thousands of people } \\
\hline & -1584 & -259 & -1325 \\
\hline & \multicolumn{3}{|l|}{ percentage (\%) } \\
\hline & 100,0 & 16.4 & 83.6 \\
\hline \multirow{4}{*}{$\begin{array}{c}2003-2010 \\
\text { (8 years) }\end{array}$} & \multicolumn{3}{|l|}{ thousands of people } \\
\hline & -1428 & -327 & -1101 \\
\hline & \multicolumn{3}{|l|}{ percentage (\%) } \\
\hline & 100,0 & 22.9 & 77.1 \\
\hline \multirow{4}{*}{$\begin{array}{c}2011-2018 \\
\text { (8 years) }\end{array}$} & \multicolumn{3}{|l|}{ thousands of people } \\
\hline & -799 & -503 & -296 \\
\hline & \multicolumn{3}{|l|}{ percentage (\%) } \\
\hline & 100,0 & 62.9 & 37.1 \\
\hline \multirow{4}{*}{$\begin{array}{l}1990-2018 \\
(29 \text { years) }\end{array}$} & \multicolumn{3}{|l|}{ thousands of people } \\
\hline & -3812 & -1090 & -2722 \\
\hline & \multicolumn{3}{|l|}{ percentage $(\%)$} \\
\hline & 100,0 & 28.6 & 71.4 \\
\hline
\end{tabular}

Source: population decline and natural decline - National Institute of Statistics, Bucharest net migration: Ghețău, V.-personal calculations

\section{Literature Review}

The decline of the population, also called "depopulation" is usually caused by events such as longterm negative demographic trends, low fertility rates, migration as a result of economic recession, urban or rural degradation or death rates due to violence, disease or other disasters. Depopulation can at the same time be beneficial for a region, which has more resources for a shrinking population. In addition to relieving the disadvantages of overpopulation, such as increased traffic, pollution, real estate prices, environmental 
destruction, etc., the GDP per capita can increase in depopulation scenarios, in addition to improving the environment quality of life indicators, such as improving air and water quality, reforestation, reducing carbon emissions, etc.

Studies that have analyzed the process of urban depopulation in recent years offer different approaches to this concept. The indicators used are different and target demographic (population loss), economic (job loss) or social (urban poverty increase) issues that are often difficult to correlate. Similarly, the terms used to refer to this process differ from country to country. In the American urban history, is used the concept of "urban decline" (Beauregard, 2003). American studies often focus on the economic dimension of decline by studying the effects of deindustrialization on cities. They also examine the impact of suburbanization on the impoverization of city centers, and connect urban sprawl, urban decline and escalating processes of socio-spatial segregation (Squires and Kubrin, 2005).

The American studies also use the term "shrinking cities" (Weaver, 1977; Breckenfeld, 1978; Rybczynski and Linneman, 1999) to describe the phenomenon. In Germany, the term "schrumpfende Städte" introduced by Häussermann and Siebel in an article published in 1988 (Florentin et al., 2009) also uses the shrinkage metaphor. At the same time, these concepts can be misleading, because in many cases, cities that are supposed to 'shrink' do not shrink, but are rather part of expanding urban agglomerations (Oswalt, 2006). It also implies a conceptualization of the decline, which is, consciously, predominantly by analyzing the territorial and demographic aspects. Some French studies use the term "rétraction urbaine," which highlights the territorial and demographic aspects of urban decline (Ducom and Yokohari, 2006).

The "Second Demographic Transition" and its Effects on Urban Spaces is a hypothesis, present in many studies, which can explain this negative evolution of certain cities, especially in Eastern Europe. According to this hypothesis, industrial societies are currently experiencing decisive demographic changes comparable in their impact to those of the first demographic transition that took place in the nineteenth century. Reduced fertility combined with rising life expectancy leads to a radical transformation of household structures and of the population as a whole (Van de Kaa, 1987).

The aging of the population, the increasing number of households, their reduced size, and their growing instability are seen to have repercussions in the spatial sphere (Champion, 2001; Ogden and Hall, 2000; Buzar et al., 2005). Based on this hypothesis, various studies in Germany (Buzar et al., 2007; Steinführer and Haase, 2007) have attempted to measure the effects of these demographic changes on the evolution of cities, in particular in Eastern Germany and beyond, in Eastern Europe. These studies reveal two apparently contradictory trends.

On the one hand, the sharp drop in fertility in these countries, described as a "demographic shock" (Steinführer and Haase, 2007), leads to rapid urban shrinkage related to the drastic reduction in natural demographic balances. The causes of this reduction in fertility are under debate: some attribute it to the second demographic transition, while others see the symptoms of the post-socialist crisis and the profound destabilization it has engendered. In addition, it is difficult to isolate the impact of the demographic factor alone in urban shrinkage, with some research also highlighting the role played by migrations and suburbanization processes (Nuissl and Rink, 2005; Kabisch et al., 2006; Steinführer and Haase, 2007).

A second tendency formulated in studies of the effects of the second demographic transition runs in a direction opposing urban decline. The growing share of smaller and single-person households, delayed childbearing combined with the rising rate of women in the workplace, the growing number of dual-income households remaining childless for longer periods, are all seen to contribute to the "reurbanization" of city centers, which are repopulating with younger households attracted by the cultural and entertainment offers available in urban centers (Ogden and Hall, 2000; Buzar et al., 2007; Steinführer and Haase, 2007).

According to product life cycle theory, every product develops following the same sequence, from initial development to growth, maturity, decline and obsolescence (Friedrichs, 1993). Thus, throughout a product's life, following a development phase, its manufacturing conditions become standardized to the point that the product can ultimately be manufactured anywhere. The resulting competition incites companies to lower their production costs by relocating, changing the product or innovating in terms of production processes (Fol and Cunningham-Sabot, 2010). The evolution of regions and urban agglomerations thus follows development cycles that include periods of rapid growth followed by periods of slower growth or of decline. Every wave of regional and urban development is seen as determined by the life cycle of the industries that are present (Booth, 1987). This theory has been used to explain the decline of industrial cities such as Detroit and Pittsburgh, according to the hypothesis that the industries that were the source of these cities' wealth had reached the final phase of their cycle (Friedrichs, 1993). Thus, according to cyclical interpretations of urban shrinkage, cities undergo phases of decline and regeneration related to their relative economic position in the larger market. At certain stages, the number of jobs decreases, which launches a process of selective migration towards other regions. The demographic decline is therefore a result of the economic decline.

Globalization is another process that is responsible for urban decline, amplifying the regional disparities among cities. The process of globalization leads to the development of a small number of "global cities" (Amin and Thrift, 1994; Dicken, 2003) that combine financial and high-level service businesses, and 
information and communication networks. Private investment is concentrated in the regions and cities that have both quality infrastructures and a high density of human capital and of existing networks between economic players. In particular, capital cities and large metropolitan regions can draw relative advantage from their concentration of political, economic and cultural institutions. On the other hand, globalization is also the cause of the decline of many industrial cities which are not able to make a place for themselves in an era of internationalized economic competition. Cities whose development was based on a single industry or on a concentration of businesses in the same sector have been particularly harmed by these changes (Bontje, 2004).

In Europe the process of urban shrinkage has spread rapidly. From 1996 to 2001, one-third of cities in the European Union lost population. According to Turok and Mykhnenko (2007), at the end of the 1990s, Europe had more shrinking cities than cities with demographic growth. This decline is especially apparent in the countries of Eastern Europe, in particular Romania, Bulgaria, the Baltic states and, with more variation depending on the cities, in Hungary, Poland and the Czech Republic. Among the shrinking cities identified by Turok and Mykhnenko (2007), the vast majority are located in Russia, Ukraine, Poland, Romania and Eastern Germany.

In Eastern Europe, the combined effects of deindustrialization, suburbanization, post-Soviet restructuring and the demographic factor all contribute to a model of unprecedented decline (Oswalt, 2006). The post-socialist transition has thus destabilized cities' economic, demographic and spatial structure, leading to new forms of urban decline and residential segregation.

Today, the cities of Eastern Europe are subject to the same structural transformations as their Western counterparts: they face similar challenges arising from deindustrialization, socio-spatial polarization phenomena and urban sprawl. The importance of the demographic factor is particularly apparent in analyses of urban shrinkage in Eastern Europe.

\section{Objectives and Methodology}

The demographic data provided by National Institute of Statistics in Romania are aggregations of those registered for each settlement: births, deaths, marriages, divorces, changes of domicile/residence inside the country, emigration and immigration. A thorough analysis of the natural decline of the population and of the internal migration with change of domicile in each settlement highlights dramatic dimensions of the depopulation phenomenon, the latter component not appearing in the general picture of the Romanian decline, by means of zero net migration. In order to determine the entire change (increase or decrease) of the number of resident population in settlements, the contribution of external migration with change of habitual residence (place of residence of at least 12 months), the number of immigrants and emigrants are also necessary.

Unfortunately, the National Institute of Statistics does not have statistical tools for recording this migration for the settlements. There are only estimates for the counties, which allows determination of the resident population by counties, with an unknown degree of accuracy. Only the future census of the population (in 2021) will probably allow us to know exactly the number of the resident population by settlements, counties, regions and for the entire country (admitting a different preparation and development than those of the 2011 census).

In this context, we used the data provided by INS Bucharest, which targets the population of the counties and capital cities of them, the major objectives of the study being:

- identification of the demographic trend in each county capital city and of the entire urban population in each county during the period 1992-2019 and their classification according to the dimension of the demographic decline;

- the analysis of the dynamics of the balance of the changes of domicile in the urban areas during 1992-2018 and their interpretation according to the demographic evolution of the urban population;

- analysis of the evolution of the natural balance of the population during 1992-2018 in the urban areas and its interpretation according to the demographic evolution and the migratory balance;

- quantifying effects with a negative impact on medium and long term on the urban population in Romania, by analyzing the dynamics of demographic aging and average age in the period 1992-2019.

The methods used to carry out this study were classical. We used the method of analysis, cartographic and comparative. The graphic and cartographic materials, indispensable to all researches, were made using available softwares in order to illustrate and compare the information suggestively (ArcGis 10.1, Microsoft Excel)

\section{Results and Discussion}

The dynamics of the urban population analyzed for the counties in Romania between 1992-2018, reflects that 28 counties and Bucharest (69\%) registered a decrease of the urban population, being between $18.1 \%$ in Teleorman County and $-0,8 \%$ in Mures County (Figure 1 ). 
Figure 1. Dynamics Of The Urban Population In The Counties (A) And Capital Cities (B) In Romania During 1992-2018
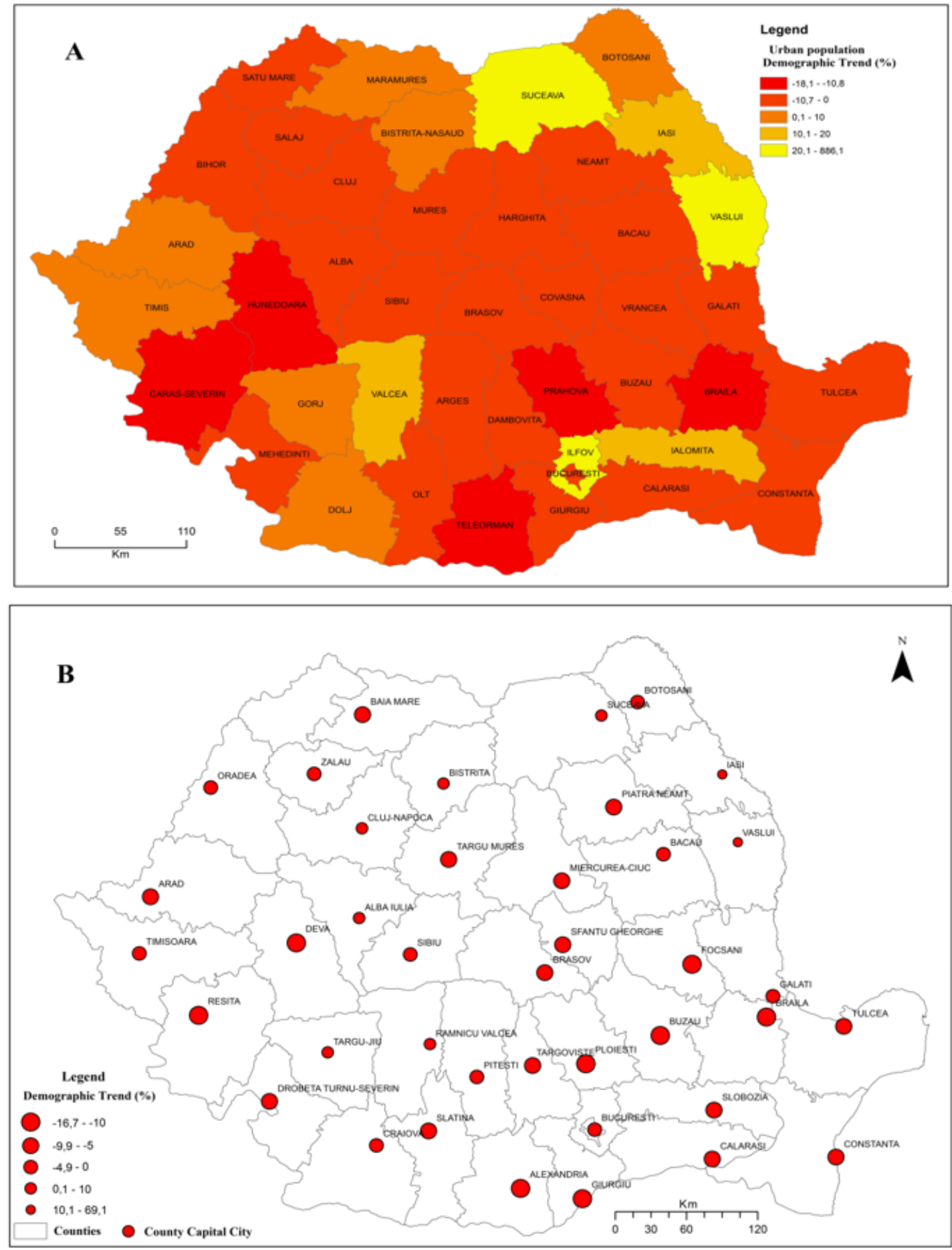

Source: INS, Bucharest, map made in ArcGis 10.1

Of these, 24 administrative-territorial units, including the Bucharest (57.1\%) registered a decrease of the urban population less than $10 \%$. The same analysis reflects that only 13 counties $(30.9 \%)$ registered an increase of the urban population between $0.7 \%$ - Dolj County and $886 \%$ - Ilfov County.

The analysis of the population evolution during the period 1992-2019 for the county capital cities, the largest urban settlements in Romania, shows an even more unfavorable evolution, 32 of them (78\%) registering a decrease between $-1,4 \%$ - Sibiu and $-16.7 \%$ - Alexandria. Most of the capital cities, 23 cities $(56 \%)$ registered a decrease of the population below $10 \%$. At the same time, only 8 cities $(19.5 \%)$ recorded an increase between 1.1\% -Tg.Jiu and 69.1\% -Vaslui, while Zalău had a steady evolution. 
Figure 2. Dynamics of The Balance (\%o) Of The Changes Of Domicile (A) And Of The Natural Balance (B) Of The Urban Population In The Counties Of Romania During 1992-2018

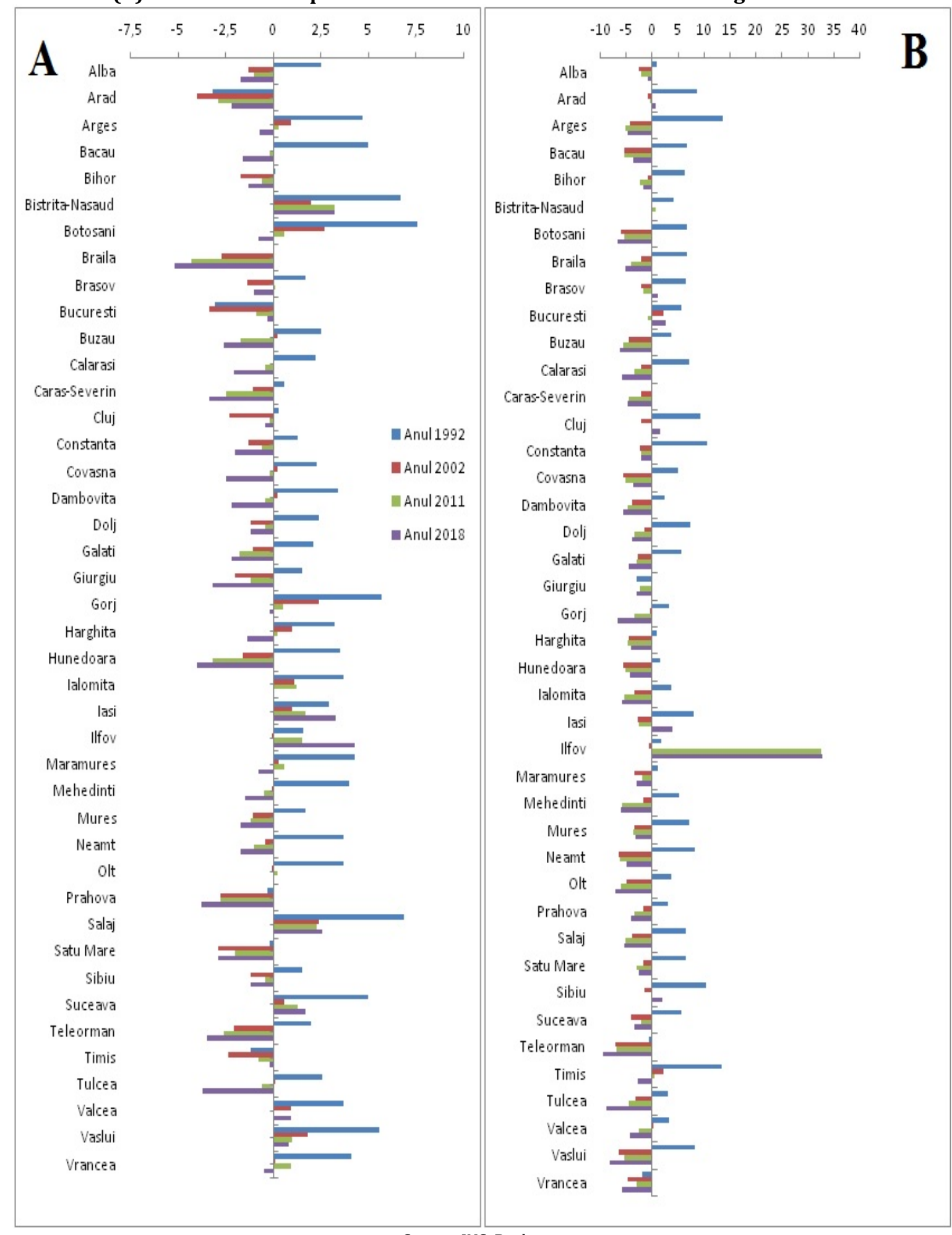

Source: INS, Bucharest

This evolution, both negative and positive, was undoubtedly caused by the dynamics of the natural balance and the migratory balance of the population during the same period, being an almost perfect correlation between them (Figure 2).

The Romanians' perception of the short and medium term evolution of the economic and social indicators has led to an alarming increase of the departures from the country. These people want to improve the quality of life for themselves and their families. The stability of family relationships through their reunion abroad also has an important influence on the migratory balance and the decrease of the population in the Romanian cities. In addition to external migration, in recent years there has been an upward internal mobility, urban-urban and, rarely, rural-urban migration. 
Figure 3. The Share of The Elders in 2019 (A) And The Elderly Population Dynamics During 19922019 (B) In Urban Regions In The Romanian Counties
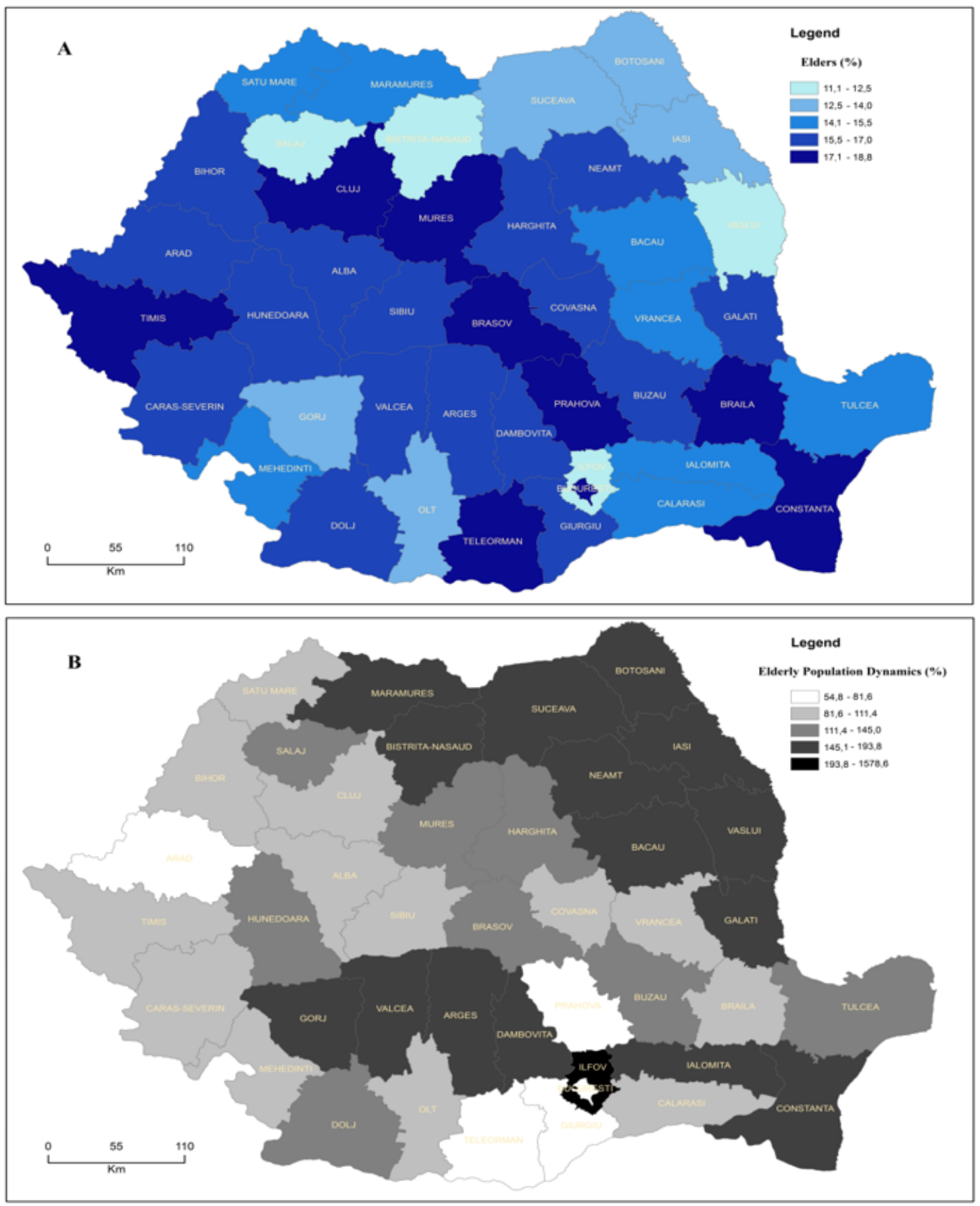

Source: INS, Bucharest, map made in ArcGis 10.1

Thus, Bucharest, Cluj-Napoca, Iași, are the cities that attract most of the young manpower, for salaries whose value exceeds the national average, which determines an accelerated demographic decline of the other municipalities and cities in Romania and accentuates the gaps of regional development.

A special case is represented by the cities in Ilfov County, which due to their position in the proximity of Bucharest, have registered a high migratory balance. Thus, the elderly population with higher financial possibilities, looking for a quieter life, less affected by pollution, but also where the prices of real estate is lower than in the national capital, has changed its domicile. 
Figure 4. The Average Age in 2019 (A) And The Average Age Dynamics During 1992-2019 (B) In Urban Regions in The Romanian
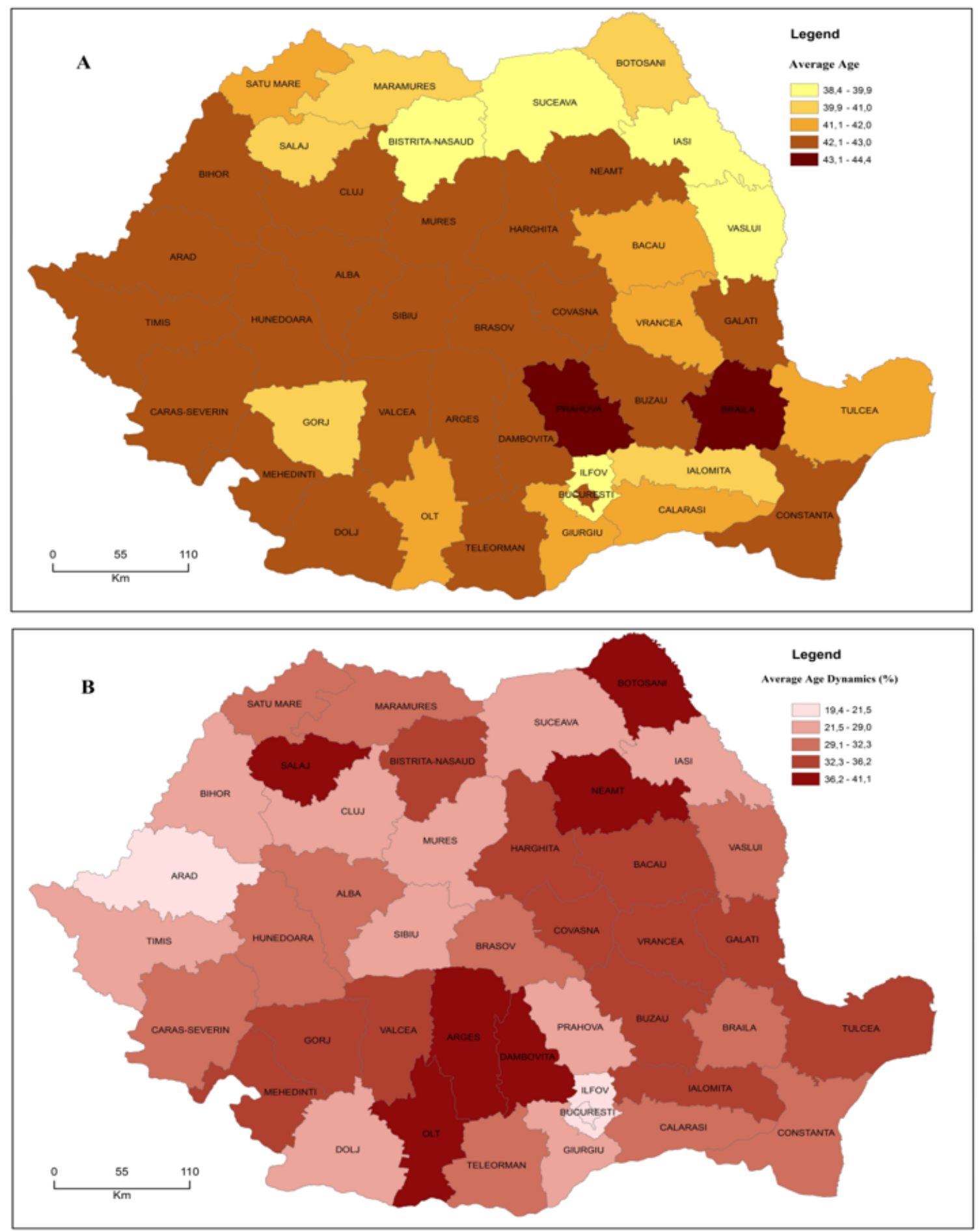

Source: INS, Bucharest, map made in ArcGis 10.1

The much lower prices and rents of the properties in the cities of Ilfov county, located in the proximity of the capital (Popești-Leordeni, Bragadiru, Pantelimon, Voluntari) were the main reason for establishing here the young adults coming from the other capital cities in Romania.

The accelerated natural deficit, especially after 1990, was also a demographic phenomenon that accentuated the depopulation at national level and implicitly in the urban regions. The causes of this unfavorable evolution of the natural balance were (Otovescu, 2019):

- the continuous decrease of the birth rate of the urban population, accompanied by the increase of the mortality rate;

- the accelerated increase of the abortion rate, especially after 1990 and maintaining high values at present;

- changes in the labor force, especially the young one, starting with 1995; 
- the difficulties of the young people to form a family and the increase of the age at which the first marriage occurs, after 25 years and even 30 years in some cases, age at which the female fertility diminishes;

- small housing, with low comfort, lack of a stable job and low incomes to ensure a decent standard of living for young couples;

- unemployment or inability to enter the labor market of a significant percentage of young people aged between 15-24 years, the unemployment rate at this age being in Romania of $15.4 \%$, while the national average was of only $4.8 \%$ (second quarter of 2017);

- ignoring the demographic decline by the local and central authorities, which after 1990 were unable to adopt a series of medium and long term pronatalist policies or to invest for the creation of jobs for young graduates of higher education;

- changing the demographic behavior of young people, who prefer to have only one child, a mentality often justified by the lack of time or low incomes.

- Simultaneous with the process of urban depopulation, is the demographic aging, reflected by the percentage of the elderly (65+) which reaches an average of $16.1 \%$ in the urban regions in Romania, but also by the average age of the population, 42.1 years in 2019 (Figure 3).

Demographic aging has a double meaning: the first refers to the situations in which a high proportion of the elderly is observed, and the second refers to the process during which this proportion is increasing.

In the urban regions of Romania, the average age of the population increased by $28.7 \%$ in the period 1992 2019, from 32.7 years to 42.1 years (Figure 4). We note, at the same time, that the urban population in 27 counties recorded an increase of the average age between 30.8\% (Satu Mare, Constanța, Alba) and 41.1\% (Botoșani). The implications of demographic aging and the increase of the average age of the urban population, as a result of depopulation, can be the following:

- the demographic implications of this process which can be contradictory, being at the same time an effect of the decrease of the birth rate but also an additional cause of it;

- the economic implications come mainly from the increase in the number of pensioners who can negatively modify the dependency index but also from the increase of the average age of the active population, with major effects on the labor productivity or on the wage expenses (the more experienced senior staff is usually better paid);

- the social implications come from the combination with feminization and impoverishment processes, in addition to the increase of the health care budget and the high risk of illness and death of the elderly population in case of medical crises caused by possible global pandemics.

\section{Conclusions}

At the origin of the urban depopulation in Romania, we can mention certain direct and indirect causes, which affect the natural balance and the mobility of the population. Among them, there are obvious the low birth rates, the high mortality rates, the high abortion rates and the migration of the young manpower.

At the same time, the loss of human resources, increases the urban decline in most of the Romanian cities and contributes to the natality and manpower decrease, as the majority of emigrants are young adults. Thus, at present, Romania is facing a deficit of human resources for the labor market.

The natural deficit, caused by low natality rates and high mortality rates, generated also a reduction in the school population and employees from Romanian urban regions, which can influence in the future, the education system and especially the national pensions fund.

Also, regional disparities were accentuated not only between urban and rural regions, but also between urban ones, in terms of salaries, pensions and quality of life. The depopulation of Romania, especially of the cities, will continue to be an irreversible process, unless it will no longer be ignored or neglected by the central and local authorities, being resolved, at the legislative and governmental level, with the help of the specialists. Thus, all the actors involved should continue to adopt efficient strategies to stop in the near future this negative process which affects the entire country.

\section{References}

1. Amin, A.; N. Thrift (1994), Globalization, Institutions and Regional Development in Europe. Oxford University Press.

2. Beauregard, R. (2003), Voices of Decline: The Postwar Fate of US Cities. Oxford: Blackwell.

3. Squires, G. D.; C. E. Kubrin (2005), Privileged Places: Race, Uneven Development and the Geography of Opportunity in Urban America, Urban Studies 42 (1):47-68.

4. Breckenfeld, G. (1978), Coping with City Shrinkage, Civil Engineering 48 (11):112-113.

5. Bontje, M. (2004), Facing the Challenge of Shrinking Cities in East Germany: The Case of Leipzig, Geojournal 61:13-21.

6. Booth, D. (1987), Regional Long Waves and Urban Policy, Urban Studies 24:447-459.

7. Buzar, S.; P. Ogden; R. Hall (2005), Households Matter: The Quiet Demography of Urban Transformation, Progress in Human Geography 29 (4):413-436.

8. Buzar, S.; P. Ogden; R. Hall; A. Haase; S. Kabisch; A. Steinführer (2007), Splintering Urban Populations: Emergent Landscapes of Reurbanisation in Four European Cities, Urban Studies 44 (4):651-677.

9. Champion, A. (2001), A Changing Demographic Regime and Evolving Polycentric Urban Regions: Consequences for the Size, Composition and Distribution of City Populations, Urban Studies 38 (4):657-677 
10. Dicken, P. (2003), Global Shift: Reshaping the Global and Economic Map in the 21st Century. New York: Guilford Press

11. Docquier, F.; Rapoport, H. (2012), Globalization, Brain Drain, and Development. Journal of Economic Literature 50(3): 681-730.

12. Ducom, E.; M. Yokoari (2006), L'Involution démographique et urbaine dans l'aire tokyoüte: Le déclin de la ville nouvelle de Tama, Les Annales de la recherche urbaine 100:23-27.

13. Florentin, D.; S. Fol; H. Roth (2009), La 'Stadtschrumpfung' ou 'rétrécissement urbain' en Allemagne: un champ de recherche émergent, Cybergeo, Espace, Société, Territoire, article 445. Last modified April 7, http://www.cybergeo.eu /index22123.html.

14. Florida, R. (2002), The Economic Geography of Talent. Annals of the Association of American Geographers 92(4): 743-755

15. Fol S.; Cunningham-Sabot E. (2010) Déclin urbain et Shrinking Cities: une évaluation critique des approches de la décroissance urbaine, Annales de géographie 2010/4 (No 674), Armand Colin, p. 359-383.

16. Friedrichs, J. (1993), A Theory of Urban Decline: Economy, Demography and Political Elites, Urban Studies 30 (6):907-917.

17. González-Leonardo, M.; López-Gay, A.; Recaño, J. (2019), Brain Drain and the Second Wave of Depopulation, Perspectives Demogràfiques 16: 1-4.

18. Kabisch, S.; A. Haase; D. Haase (2006), Beyond Growth: Urban Development in Shrinking Cities as a Challenge for Modeling Approaches, UFZ, Center for Environmental Research.

19. Nuissl, H.; D. Rink (2005), The 'Production' of Urban Sprawl: Urban Sprawl in Eastern Germany as a Phenomenon of Post-Socialist Transformation, Cities 22

20. Ogden, P.; R. Hall (2000), Households, Reurbanisation and the Rise of Living Alone in the Principal French Cities, Urban Studies 37 (2):367-390.

21. Oswalt, P. (2006), Shrinking Cities Vol. 1. International Research. Ostfildern-Ruit, Germany: Hatje Cantz Verlag.

22. Rybczynski, W.; P. Linneman (1999), How to Save our Shrinking Cities, Public Interest 135:30-44.

23. Otovescu C.; Otovescu A. (2019), The Depopulation of Romania -Is It an Irreversible Process?, Revista de cercetare și intervenție socială, 2019, vol. 65, pp. 370-388

24. Sassen, S. (1991), The Global City. Princeton, Princeton University Press

25. Sánchez-Moral, S.; Arellano, A.; Díez-Pisonero, R. (2018), Interregional Mobility of Talent in Spain: The Role of Job Opportunities and Qualities of Places during the Recent Economic Crisis. Environment and Planning A: Economy and Space 50(4): 789-808

26. Steinführer, A.; A. Haase (2007), Demographic Change as Future Challenge for Cities in East Central Europe, Journal Compilation, Swedish Society for Anthropology and Geography:183-195.

27. Turok, I.; V. Mykhnenko (2007), The Trajectories of European Cities, 1960-2005, Cities 24 (3):165-182.

28. Van de Kaa, D. (1987), Europe's Second Demographic Transition, Population Bulletin 42:1-57.

29. Weaver, R. (1977), The Suburbanization of America or the Shrinking of the Cities, Civil Rights Digest 9 (3):2-11.

30. ***http://statistici.insse.ro:8077/tempo-online/

31. ${ }^{* * *}$ http://www.contributors.ro/sinteze/dimensiuni-teritoriale-ale-depopularii-romaniei-privire-de-ansamblu-asupra-declinului$\%$ C8\%99i-depopularii-in-ultimii-30-de-ani/

32. ***file:///E:/documente/articole\%202018/2020/the-future-of-cities_online.pdf 